\title{
Synthesis and partial dehydrogenation of the impregnated lithium borohydride, $\mathrm{LiBH}_{4}$
}

\author{
Masaharu MENJO, Hai-Wen LI, Motoaki MATSUO, Kazutaka IKEDA and Shin-ichi ORIMO ${ }^{\dagger}$ \\ Institute for Materials Research, Tohoku University, 2-1-1, Katahira, Aoba-ku, Sendai 980-8577
}

$\mathrm{LiBH}_{4}$ with high hydrogen density has been attracting great interest as one of potential candidates of advanced hydrogen storage materials. A feasible way to overcome problematic issues on dehydrogenation of $\mathrm{LiBH}_{4}$, such as formation of fine powders and overflow by melting, is expected to synthesize bulk $\mathrm{LiBH}_{4}$ by applying the "impregnation method". In the present study, $\mathrm{LiBH}_{4}$ on a Ni foam with porosity of $98 \%$ homogeneously impregnated the foam at $573 \mathrm{~K}$ without changing the original bulk morphology of the foam. The morphology of the impregnated $\mathrm{LiBH}_{4}$ was also well retained, even after a partial dehydrogenation at $873 \mathrm{~K}$. Some Ni borides were found to be newly formed depending on the heating (dehydrogenation) conditions, and the formation probably dominates the microstructure and dehydrogenation property of the impregnated $\mathrm{LiBH}_{4}$.

(C2009 The Ceramic Society of Japan. All rights reserved.

Key-words : Hydrogen storage, Impregnation, Complex hydride, Borohydride, Boride

[Received December 9, 2008; Accepted February 19, 2009]

\section{Introduction}

Development of advanced hydrogen storage materials is a critical research topic for various hydrogen energy applications. ${ }^{1)}$ Metal borohydrides $M\left(\mathrm{BH}_{4}\right)_{n}(n$ (valence of metal $\left.M)=1-4\right)$, some of the complex hydrides, with high hydrogen densities have been attracting great interest as potential candidates of advanced hydrogen storage materials. ${ }^{2-10)}$ For instance, $\mathrm{LiBH}_{4}$, composed of $\mathrm{Li}^{+}$cation and $\left[\mathrm{BH}_{4}\right]^{-}$complex anion, can store about 13.8 mass $\%$ of hydrogen based on the following reversible reactions: ${ }^{11), 12)}$

$$
\mathrm{LiBH}_{4} \Leftrightarrow \mathrm{LiH}+\mathrm{B}+3 / 2 \mathrm{H}_{2} .
$$

Upon heating (from the left to the right side of the reaction (1)), $\mathrm{LiBH}_{4}$ melts at around $550 \mathrm{~K}^{2)}$ and then decomposes into $\mathrm{LiH}$ and $\mathrm{B}$ above $700 \mathrm{~K}$ accompanying the dehydrogenation (hydrogen desorption) reaction. It has been found that the dehydrogenation temperatures can be decreased by partial or full substitutions of Li by other appropriate metals or ions. ${ }^{2), 13)}$

Here, there are two problematic issues regarding the reaction (1) from the viewpoint of practical applications: One is formation of fine powders of the components, $\mathrm{LiBH}_{4}, \mathrm{LiH}$, and $\mathrm{B}$, after the reaction (possibly causing, for example, surface poisoning and lowering heat conductivity). Another is "overflow" of the melted $\mathrm{LiBH}_{4}$ from sample containers.

A feasible way to overcome these issues is to synthesize bulk $\mathrm{LiBH}_{4}$ by applying the "impregnation method" as an advanced material processing for complex hydrides. We have previously applied this method to $\mathrm{LiNH}_{2}{ }^{14), 15)}$ The bulk $\mathrm{LiNH}_{2}$ which impregnated $\mathrm{Ni}$ foam (impregnated $\mathrm{LiNH}_{2}$ ) did not change into the fine powders and it retained the bulk morphology even after ten reversible reactions, storing about 6 mass \% of hydrogen.

In the present paper, we report the preliminary results on the synthesis of the impregnated $\mathrm{LiBH}_{4}$ and the dehydrogenation property by heating.

Corresponding author: S. Orimo; E-mail: orimo@imr.tohoku.ac.jp

\section{Experimental}

A schematic drawing of the setup is shown in Fig. 1. Ni foam (Sumitomo Electric Industries, Ltd., porosity of $98 \%$, pore size of $100-500 \mu \mathrm{m}$, thickness and diameter of about $1.5 \mathrm{~mm}$ and 10 $\mathrm{mm}$, respectively) was used as a matrix for impregnation, as in the previous study on $\mathrm{LiNH}_{2} \cdot{ }^{14), 15)}$ In a glove box with circulating catalytically purified argon (dew point below $183 \mathrm{~K}$ ), pelletshaped $\mathrm{LiBH}_{4}$ (Aldrich Co., Ltd., 95.0\% purity) placed on top of the Ni foam was installed in a reaction container. The container was sealed and then heated up to $573 \mathrm{~K}$ for 120 min under a hydrogen (99.99999\%-purity) pressure of 0.5 MPa. During the process, the pellet-shaped $\mathrm{LiBH}_{4}$ melted and impregnated the $\mathrm{Ni}$ foam. The samples before and after the impregnation were characterized by optical and scanning electron microscopy observa-

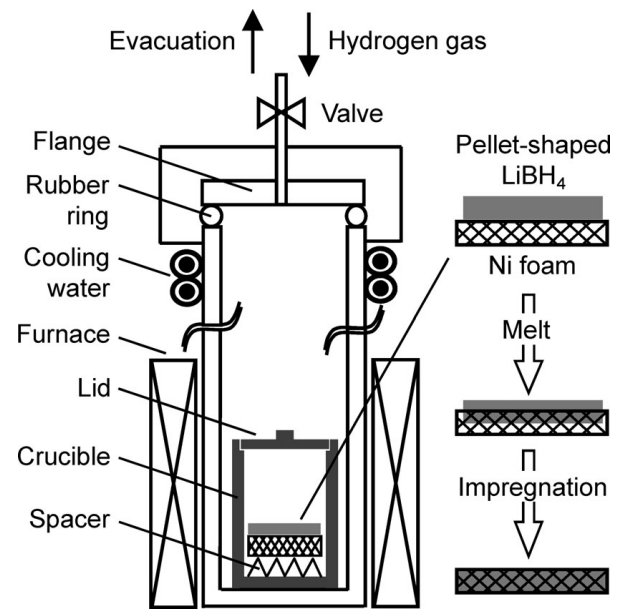

Fig. 1. Schematic drawing of the setup for the impregnation method. Pellet-shaped $\mathrm{LiBH}_{4}$ is placed on top of the Ni foam for impregnation. By heating, this pellet melts and impregnates the Ni foam. A bellowsshaped Ni foil is used as a "spacer" to avoid any direct contact between the $\mathrm{Ni}$ foam and the bottom of the crucible. 
tions, gas chromatography (heating rate of $5 \mathrm{~K} / \mathrm{min}$ up to $873 \mathrm{~K}$, Ar flow), Raman spectroscopy (532-nm laser), and powder X-ray diffraction measurement $(\mathrm{Cu} \mathrm{K} \alpha)$. The samples were always handled in the glove box without exposure to air.

\section{Results and discussion}

The optical and scanning electron microscopy images of the $\mathrm{Ni}$ foam before and after the impregnation are shown in Fig. 2, respectively. The images indicate that $\mathrm{LiBH}_{4}$ homogeneously impregnated the $\mathrm{Ni}$ foam without changing the original bulk morphology of the foam. Overall dehydrogenation property by heating was analyzed by gas chromatography. As shown in Fig. 3, the impregnated $\mathrm{LiBH}_{4}$ has a narrower dehydrogenation temperature range comparing with that of the conventional $\mathrm{LiBH}_{4}$. Also, small and irregular dehydrogenation reaction around 650

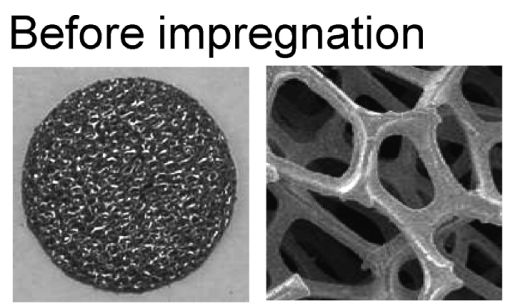

After impregnation

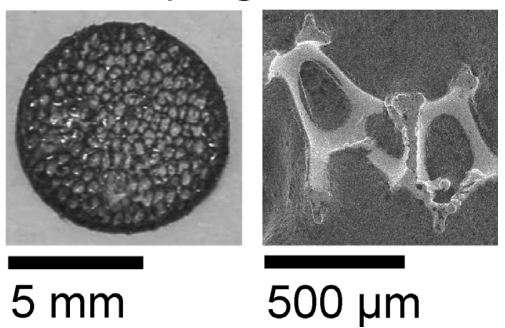

Fig. 2. Optical microscopy (left) and scanning electron microscopy (right) images of the $\mathrm{Ni}$ foam, before and after the impregnation of $\mathrm{LiBH}_{4}$, respectively. $\mathrm{LiBH}_{4}$ homogeneously impregnated the $\mathrm{Ni}$ foam without changing the original bulk morphology of the foam.

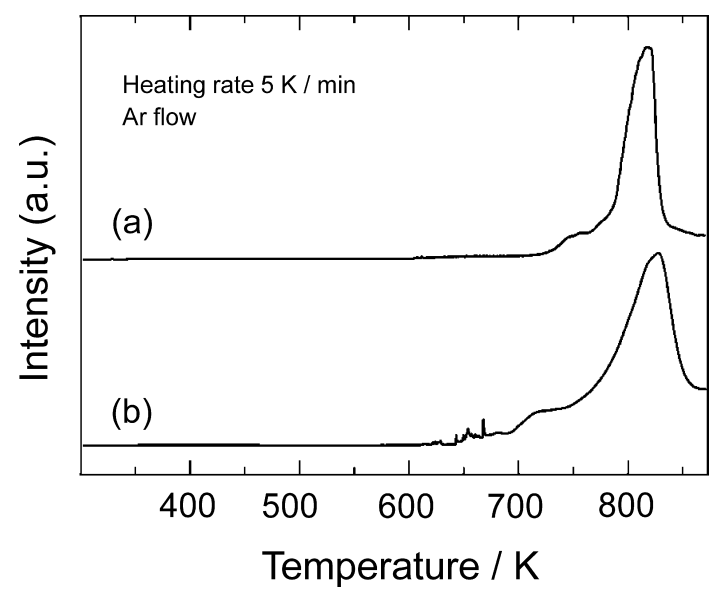

Fig. 3. Profiles of gas chromatography corresponding to dehydrogenation reactions of (a) the impregnated $\mathrm{LiBH}_{4}$ and (b) the conventional $\mathrm{LiBH}_{4}$. Small and irregular peaks around $650 \mathrm{~K}$ only detected in (b) are probably coming from the "overflow" of the melted $\mathrm{LiBH}_{4}$ from the sample containers.

$\mathrm{K}$, probably coming from the overflow of the melted $\mathrm{LiBH}_{4}$ from the sample containers, cannot be detected in the impregnated $\mathrm{LiBH}_{4}$. Moreover the bulk morphology was well retained after the heating, as summarized in Fig. 4. Thus, the two problematic issues mentioned in Introduction might be possibly solved by applying the "impregnation method" to $\mathrm{LiBH}_{4}$. (The change of the microstructures also observed in Fig. 4 relates to the formation of Ni borides, explained later.)

Raman spectroscopy detecting $\mathrm{B}-\mathrm{H}$ bonding and vibration features is quite useful to investigate $\mathrm{LiBH}_{4}$ and the derived complex hydrides. ${ }^{2), 16)-18)}$ The actual Raman spectra of the samples corresponding to the images shown in Figs. 4(a)-(e) are summarized in Fig. 5. By the comparison with the calculated phonon density of state (DOS) shown in the inset of Fig. $5,{ }^{16)-18)}$ the spectra can be identified as either $\mathrm{LiBH}_{4}$ or $\mathrm{Li}_{2} \mathrm{~B}_{12} \mathrm{H}_{12}$. The spectrum of $\mathrm{LiBH}_{4}$ in the sample after the heating at $773 \mathrm{~K}$ (Fig. 5(b)) is the almost same as that in the sample just after the impregnation (Fig. 5(a)). On the other hand, different spectra can be clearly detected in the samples after the heating at $873 \mathrm{~K}$ (Figs. 5(c)-(e)).

(a)

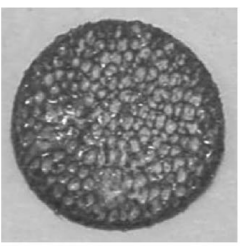

(b)

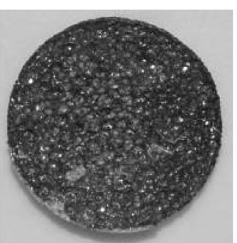

(c)

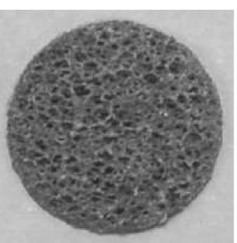

(d)

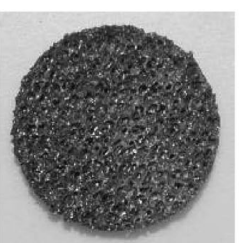

(e)

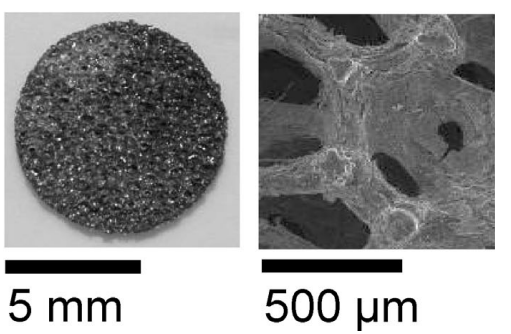

Fig. 4. Optical microscopy (left) and scanning electron microscopy (right) images; (a) after impregnation of $\mathrm{LiBH}_{4}$ (same to the lower image in Fig. 2), after the heating at (b) $773 \mathrm{~K}$ for $5 \mathrm{~min}, 873 \mathrm{~K}$ for (c) $5 \mathrm{~min}$, (d) $60 \mathrm{~min}$, and (e) $120 \mathrm{~min}$ under a hydrogen pressure of $1 \mathrm{MPa}$, respectively. The bulk morphology was well retained after the heating. 


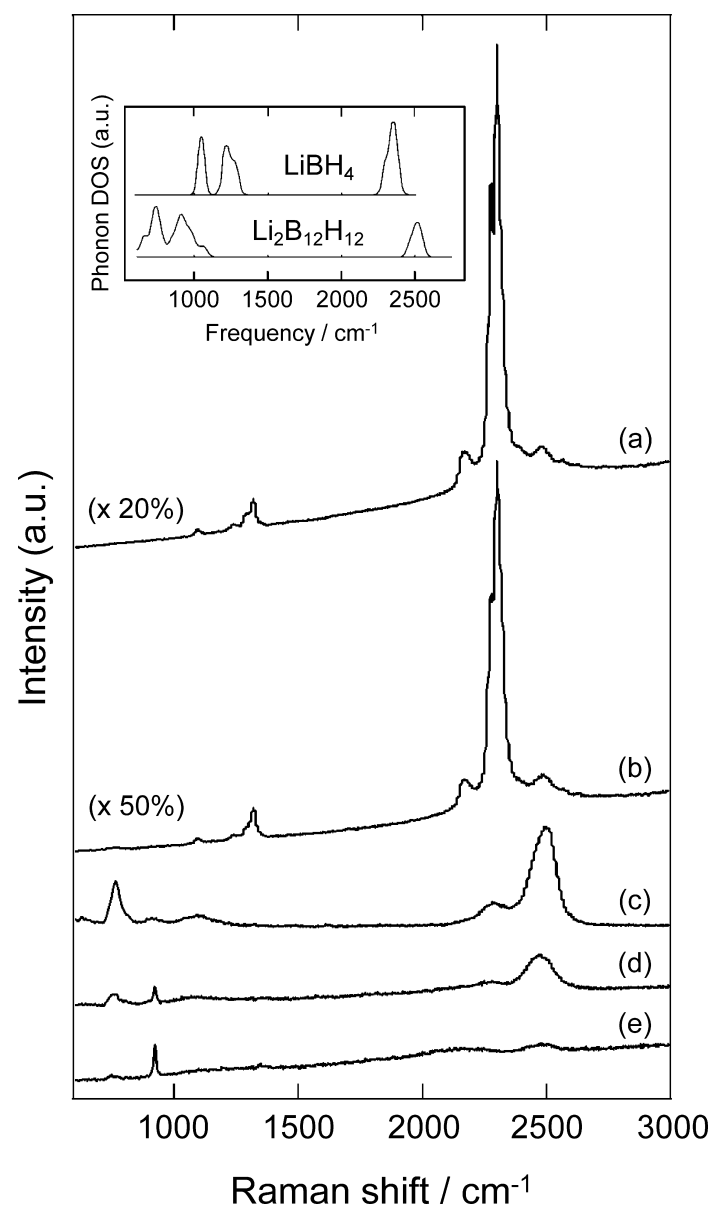

Fig. 5. Raman spectra of the samples corresponding to those shown in Figs. 4(a)-(e). By the comparison with the calculated phonon density of state (DOS) shown in the inset, ${ }^{16-18)}$ the spectra can be identified as either $\mathrm{LiBH}_{4}$ or $\mathrm{Li}_{2} \mathrm{~B}_{12} \mathrm{H}_{12}$. (a) and (b) correspond to the spectra of $\mathrm{LiBH}_{4}$, and (c)-(e) mainly of $\mathrm{Li}_{2} \mathrm{~B}_{12} \mathrm{H}_{12}$. (The intensity of (a) and (b) was decreased by $20 \%$ and $50 \%$, respectively.)

These spectra originate from $\mathrm{Li}_{2} \mathrm{~B}_{12} \mathrm{H}_{12}$, composed of $\mathrm{Li}^{+}$cation and $\left[\mathrm{B}_{12} \mathrm{H}_{12}\right]^{2-}$ complex anion, formed according to the following reaction: ${ }^{17)-20)}$

$$
\mathrm{LiBH}_{4} \rightarrow 1 / 12 \mathrm{Li}_{2} \mathrm{~B}_{12} \mathrm{H}_{12}+5 / 6 \mathrm{LiH}+13 / 12 \mathrm{H}_{2} .
$$

This result suggests that the decomposition and partial dehydrogenation reactions (2) occurred at $873 \mathrm{~K}$.

Each the sample was crushed into powder in the glove box, and powder X-ray diffraction measurement was carried out. The results are summarized in Fig. 6, and agree well with those of the Raman spectroscopy; that is, the diffraction peaks from $\mathrm{LiBH}_{4}$ disappeared by heating at $873 \mathrm{~K}$. It can be noted that due to the reaction of the $\mathrm{Ni}$ foam and $\mathrm{B}$ from $\mathrm{LiBH}_{4}$ and/or $\mathrm{Li}_{2} \mathrm{~B}_{12} \mathrm{H}_{12}$, diffraction peaks of some $\mathrm{Ni}$ borides $\left(\mathrm{Ni}_{3} \mathrm{~B}, \mathrm{Ni}_{2} \mathrm{~B}\right.$, and $\mathrm{Ni}_{4} \mathrm{~B}_{3}$ ) newly formed depending on the heating (dehydrogenation) conditions. The formation of the Ni borides is considered to dominate not only the microstructure observed in Fig. 4 and but also the specific dehydrogenation property described above. Systematic investigations including the promotion of the reversible dehydrogenation and rehydrogenation of the impregnated $\mathrm{LiBH}_{4}$ is highly required.

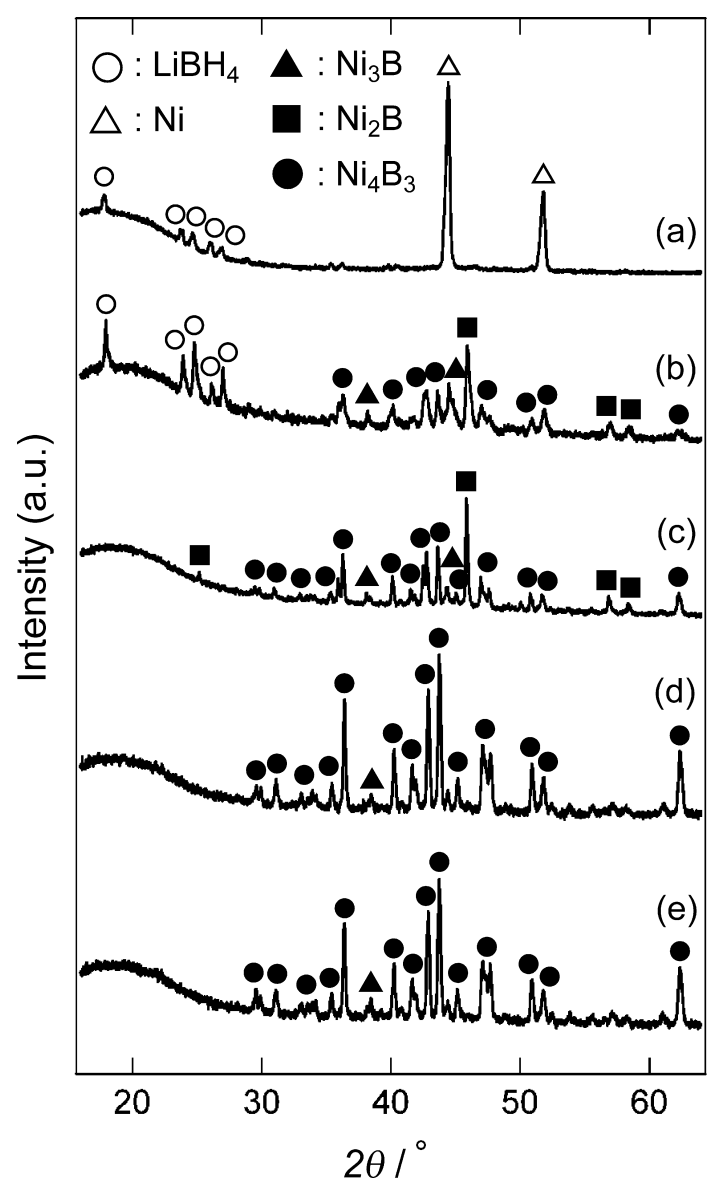

Fig. 6. Powder X-ray diffraction profiles of the samples corresponding to those shown in Figs. 4(a)-(e) and 5(a)-(e). Broad uphill at about $20^{\circ}$ originates from glass substrate used for measurement. Some Ni borides were found to be newly formed depending on the heating (dehydrogenation) conditions.

\section{Conclusions}

Preliminary results on the synthesis of the bulk $\mathrm{LiBH}_{4}$ which impregnated into Ni foam (impregnated $\mathrm{LiBH}_{4}$ ) and the dehydrogenation property by heating were reported. Pellet-shaped $\mathrm{LiBH}_{4}$ homogeneously impregnated the $\mathrm{Ni}$ foam at $573 \mathrm{~K}$ without changing the original bulk morphology of the foam, which was also well retained after the partial dehydrogenation at $873 \mathrm{~K}$. The impregnated $\mathrm{LiBH}_{4}$ has the narrower dehydrogenation temperature range comparing with that of the conventional $\mathrm{LiBH}_{4}$. Also, small and irregular dehydrogenation reaction around $650 \mathrm{~K}$, probably coming from the overflow of the melted $\mathrm{LiBH}_{4}$ from the sample containers, cannot be detected in the impregnated $\mathrm{LiBH}_{4}$. Thus, the two problematic issues mentioned in Introduction might be possibly solved by applying the "impregnation method" to $\mathrm{LiBH}_{4}$. Some $\mathrm{Ni}$ borides $\left(\mathrm{Ni}_{3} \mathrm{~B}, \mathrm{Ni}_{2} \mathrm{~B}\right.$, and $\left.\mathrm{Ni}_{4} \mathrm{~B}_{3}\right)$ were found to be newly formed depending on the heating (dehydrogenation) conditions, and the formation probably dominates the microstructure and dehydrogenation property of the impregnated $\mathrm{LiBH}_{4}$.

Acknowledgements This work was financially supported by Global COE Program "Materials Integration, Tohoku University," and by the Collaboration Research with Electric Power Development Co., Ltd., (J-Power). The authors would like to acknowledge to Mr. T. Haga and Mr. T. Kikuchi for their helpful discussions. 


\section{References}

1) S. Orimo, Y. Nakamori, J. R. Eliseo, A. Züttel and C. M. Jensen, Chem. Rev., 107, 4111-4132 (2007).

2) Y. Nakamori and S. Orimo, J. Alloys Comp., 370, 271-275 (2004).

3) L. Schlapbach and A. Züttel, Nature, 414, 353-358 (2001).

4) A. Züttel, P. Wenger, S. Rentsch, P. Sudan, Ph. Mauron and Ch. Emmenegger, J. Power Sources, 118, 1-7 (2003).

5) W. Grochala and P. P. Edwards, Chem. Rev., 104, 1283-1316 (2004).

6) M. Au and A. Jurgensen, J. Phys. Chem. B, 110, 7062-7067 (2006).

7) M. Au, A. Jurgensen and K. Zeigler, J. Phys. Chem. B, 110, 26482-26487 (2006).

8) X. B. Yu, Z. Wu, Q. R. Chen, Z. L. Li, B. C. Weng and T. S. Huang, Appl. Phys. Lett., 90, 034106-1-3 (2007).

9) H.-W. Li, K. Kikuchi, Y. Nakamori, N. Ohba, K. Miwa, S. Towata and S. Orimo, Acta Mater., 56, 1342-1347 (2008).

10) T. Sato, K. Miwa, Y. Nakamori, K. Ohoyama, H.-W. Li, T. Noritake, M. Aoki, S. Towata and S. Orimo, Phys. Rev. B, 77, 104114-1-8 (2008).

11) A. Züttel, S. Rentsch, P. Fischer, P. Wenger, P. Sudan, Ph. Mauron and Ch. Emmenegger, J. Alloys Comp., 356-357, 515-520 (2003).
12) S. Orimo, Y. Nakamori, G. Kitahara, K. Miwa, N. Ohba, S. Towata and A. Züttel, J. Alloys Comp., 404-406, 427-430 (2005).

13) Y. Nakamori, K. Miwa, A. Ninomiya, H.-W. Li, N. Ohba, S. Towata, A. Züttel and S. Orimo, Phys. Rev. B, 74, 045126-19 (2006).

14) T. Hao, M. Matsuo, Y. Nakamori and S. Orimo, J. Alloys Comp., 458, L1-L5 (2008).

15) M. Menjo, T. Hao, M. Matsuo, Y. Nakamori and S. Orimo, J. Japan Inst. Metals, 72, 163-167 (2008).

16) K. Miwa, N. Ohba, S. Towata, Y. Nakamori and S. Orimo, Phys. Rev. B, 69, 245120-1-8 (2004).

17) S. Orimo, Y. Nakamori, N. Ohba, K. Miwa, M. Aoki, S. Towata and A. Züttel, Appl. Phys. Lett., 89, 021920-1-3 (2006).

18) N. Ohba, K. Miwa, M. Aoki, T. Noritake, S. Towata, Y. Nakamori, S. Orimo and A. Züttel, Phys. Rev. B, 74, 0751101-7 (2006).

19) H.-W. Li, K. Kikuchi, T. Sato, Y. Nakamori, N. Ohba, M. Aoki, K. Miwa, S. Towata and S. Orimo, Mater. Trans., 49, 2224-2228 (2008).

20) S. J. Hwang, R. C. Bowman, Jr., J. W. Reiter, J. Rijssenbeek, G. L. Soloveichik, J. C. Zhao, H. Kabbour and C. C. Ahn, J. Phys. Chem. C, 112, 3164-3169 (2008). 